\title{
BMJ
}

\section{Baseline self reported functional health and vulnerability to post-traumatic stress disorder after combat deployment: prospective US military cohort study}

\author{
Cynthia A LeardMann, senior biostatistician, ${ }^{1}$ Tyler C Smith, director, ${ }^{1}$ Besa Smith, senior epidemiologist/ \\ biostatistician, ${ }^{1}$ Timothy S Wells, medical chief epidemiologist, ${ }^{2}$ Margaret A K Ryan, occupational and \\ preventive medicine physician ${ }^{3}$ for the Millennium Cohort Study Team
}

$\overline{{ }^{1} \text { Department of Defense Center for }}$ Deployment Health Research, Naval Health Research Center, 140 Sylvester Road, San Diego, CA 92106, USA

${ }^{2}$ Biosciences and Protection Division, Air Force Research Laboratory, Wright-Patterson Air Force Base, 2800 Q Street, OH 45433, USA.

${ }^{3}$ Naval Hospital Camp Pendleton, Box 555191, CA 92055, USA

Correspondence to: $\mathrm{C}$ LeardMann Cynthia.LeardMann@med.navy.

mil

Cite this as: BMJ 2009;338:b1273 doi:10.1136/bmi.b1273

\section{ABSTRACT}

Objective To determine if baseline functional health status, as measured by SF-36 (veterans), predicts new onset symptoms or diagnosis of post-traumatic stress disorder among deployed US military personnel with combat exposure.

Design Prospective cohort analysis.

Setting Millennium Cohort.

Participants Combat deployed members who completed baseline (2001-3) and follow-up (2004-6)

questionnaires. Self reported and electronic data used to examine the relation between functional health and posttraumatic stress disorder.

Main outcome measures New onset post-traumatic stress disorder as measured by either meeting the DSM-IV criteria with the 17 item post-traumatic stress disorder checklist-civilian version or self report of a physician diagnosis at follow-up with the absence of both at baseline.

Results Of the 5410 eligible participants, 395 (7.3\%) had new onset symptoms or diagnosis of post-traumatic stress disorder at the time of follow-up. Individuals whose baseline mental or physical component summary scores were below the 15 th centile had two to three times the risk of symptoms or a diagnosis of post-traumatic stress disorder by follow-up compared with those in the 15th to 85 th centile. Of those with new onset symptoms or diagnosis of post-traumatic stress disorder, over half (58\%) of cases occurred among participants with scores below the 15 th centile at baseline.

Conclusions Low mental or physical health status before combat exposure significantly increases the risk of symptoms or diagnosis of post-traumatic stress disorder after deployment. More vulnerable members of a population could be identified and benefit from interventions targeted to prevent new onset posttraumatic stress disorder.

\section{INTRODUCTION}

Post-traumatic stress disorder (PTSD) is associated with various adverse health effects, including reduced functional health and quality of life. ${ }^{1-9}$ Individuals with
PTSD also report more physical symptoms and comorbidities than those without PTSD ${ }^{8-13}$ A prospective study among veterans of the 1991 Gulf war found that symptoms of PTSD measured directly after return from deployment predicted self reported health problems two years later. ${ }^{14}$ Most previous studies, however, have primarily used cross sectional or retrospective data, making it difficult to ascertain the effects of decreased mental or physical health on new onset or persistent symptoms of PTSD. It has not been temporally established, therefore, if those with poor mental or physical health status are more vulnerable to developing PTSD. A meta-analysis of risk factors for PTSD, based mostly on retrospective data, however, found that psychiatric history, life stress, and other previous traumas were not risk factors for the development of PTSD among military service members. ${ }^{15}$ In a more recent meta-analysis, factors before the trauma, perceived threat, and social support were all significant predictors, yet the strongest predictors were psychological processes during the traumatic event. ${ }^{16}$ One recent prospective cohort study found that young adults (aged 20-23) with high levels of anxiety or depression in first grade (age 6-7) were 1.5 times more likely to develop PTSD after a traumatic event compared with other young adults with low levels of anxiety and depression in first grade who later experienced a traumatic event. ${ }^{17}$ Another prospective study, that used data from the Millennium Cohort Study, reported a twofold increased risk of new onset symptoms of PTSD at follow-up among those who reported previous assault compared with those who reported no previous assault at baseline. ${ }^{18}$

The Millennium Cohort Study began collecting baseline data in July 2001, before the start of the current wars in Afghanistan and Iraq, and obtained followup data from June 2004 to February 2006. A recent study that also used data from this cohort suggested that exposures to combat, as opposed to deployment itself, leads to a significantly increased risk of new onset PTSD among service members returning from the current conflicts. ${ }^{19}$ On the basis of those findings we 
examined whether baseline mental or physical health, as measured by the medical outcomes study SF-36 health survey for veterans (SF-36V), predicts new onset symptoms or diagnosis of PTSD among those service members who are at the highest risk of developing new onset PTSD - that is, those who have deployed in support of the current conflicts and reported combat exposure.

\section{METHODS}

\section{Study population}

The Millennium Cohort Study, a 21 year longitudinal study, was launched in 2001 to gather and evaluate data on behavioural and occupational characteristics related to military service that might be associated with adverse health. ${ }^{2021}$ The invited cohort was randomly selected from all US military personnel serving in October 2000, oversampling those who had been previously deployed to south west Asia, Bosnia, or Kosovo (1 January 1998 to 1 September 2000), members of the Reserve and National Guard, and women to ensure sufficient power to detect differences in smaller subgroups. The 77047 consenting participants who enrolled in this first panel between July 2001 and June 2003 represent 36\% of those invited. Investigations of potential biases found the Millennium Cohort to be well representative with participants reporting reliable data and not influenced to participate by poor health before enrolment. ${ }^{22-29} \mathrm{~A}$ more in depth description of the methods has been reported elsewhere. ${ }^{21}$ Of the 77047 participants who enrolled in the first panel, $55021(71 \%)$ completed the first follow-up questionnaire between June 2004 and February 2006. Analyses of potential responder bias to the first follow-up are ongoing. Demographic and military specific data were obtained from electronic personnel files, including sex, birth date, highest education level, marital status, race/ethnicity, deployment experience in support of wars in Iraq and Afghanistan, pay grade, service component (active duty and Reserve/National Guard), service branch (army, air force, navy, coast guard, and marine corps), and military occupation (combat specialist, healthcare specialist, functional support, and others).

As service members exposed to combat are at the highest risk of PTSD after deployment, ${ }^{19}$ we included only participants who reported combat-like exposures. We defined this as personal exposure to at least one of the following experiences in the three years before completion of the follow-up questionnaire: witnessing a person's death due to war, disaster, or tragic event, witnessing instances of physical abuse (torture, beating, rape), dead and/or decomposing bodies, maimed soldiers or civilians, or prisoners of war or refugees. Furthermore, participants for this current study must have given informed, voluntary consent, completed the baseline (2001-3) and the first follow-up (2004-6) questionnaires, been free from symptoms and diagnosis of PTSD at baseline, had their first complete deployment in support of the wars in Iraq and Afghanistan between the baseline and first follow-up questionnaires, and had complete demographic, behavioural, military specific, and SF-36V data.

\section{Health and behaviour}

The baseline and follow-up questionnaires included questions on physical health, mental health, deployment, occupational exposures, and other health outcomes. The SF-36V, is a modified version of SF-36 and part of the Millennium Cohort questionnaire, was used to examine self reported mental and physical health status at baseline. ${ }^{30-34}$ Like the original SF-36, the SF-36V includes eight health scales, which can be summarised into mental and physical component summary scores. ${ }^{35}$ Modelled from the SF-36 formulas, the mean (SD) normative US score for each summary score is 50 (10).$^{35}$ Higher scores reflect more favourable health status. To examine if mental or physical health status before deployment, specifically extreme health, confers resiliency or vulnerability for developing PTSD after deployment among combat deployers we classified participants into three groups based on component summary scores. We decided, a priori, that the groups would be based on about $1 \mathrm{SD}$, with the highest and lowest groups representing 30\% of the study population, and the middle group representing the $70 \%$ remaining.

The Millennium Cohort questionnaire includes the PTSD checklist-civilian version (PCL-C), a 17 item self report measure of PTSD symptoms. ${ }^{3637}$ Using a 5 point Likert scale from 1 (not at all) to 5 (extremely) respondents rate the severity of each symptom during the past 30 days. We used two separate screening criteria to classify those with PTSD symptoms. The sensitive definition of PTSD symptoms uses criteria from the Diagnostic and Statistical Manual of Mental Disorders, fourth edition (DSM-IV), alone, while the specific definition requires a total score of 50 or more on a scale from 17 to 85 points (based directly on the Likert scale, where a response of "not at all" receives 1 point and "extremely" receives 5 points for each of the 17 items) in addition to meeting the DSM-IV criteria. ${ }^{37-41}$ The DSM-IV criteria for PTSD were met when a participant reported a moderate or above level of at least one intrusion symptom, three avoidance symptoms, and two hyperarousal symptoms. ${ }^{40}$ With a cut off of 50 this instrument is highly specific $(99 \%)$ but less sensitive $(60 \%),{ }^{41}$ while use of the DSM-IV criteria alone increases sensitivity $(100 \%)$ but has a lower specificity $(92 \%) .{ }^{41}$ We excluded from all analyses participants who had symptoms of PTSD at baseline, based on the specific criteria, while those who met the sensitive criteria were excluded only from the analyses based on the sensitive criteria.

At baseline, we excluded from this study any participants who answered "yes . . . post-traumatic stress disorder" to the question, "Has your doctor or other health professional EVER told you that you have any of the following conditions?" On the follow-up questionnaire, we classified participants who answered "yes ... post-traumatic stress disorder" to the question "in 
the last 3 years, has your doctor or other health professional told you that you have any of the following conditions?" as having a new diagnosis of PTSD. For the purpose of this study, we classified participants as having new onset symptoms or diagnosis of PTSD if they met the PCL-C criteria or self reported having the diagnosis on the follow-up questionnaire and were free from symptoms and a diagnosis of PTSD at baseline.

Participants who self reported at least one of the following on the baseline questionnaire were classified as alcohol/CAGE positive: a need to cut back on drinking, annoyed at anyone who suggested a reduction in drinking, a need for an "eye opener," or early morning drink, or feeling guilty about drinking. ${ }^{42}$ We categorised cigarette smoking at baseline into three groups: non-smokers, current smokers, and past smokers.

\section{Statistical analysis}

We completed a descriptive investigation of demographic, behavioural, and military specific characteristics compared with baseline self reported health status. Univariate analyses compared characteristics and categories of mental and physical component summary scores between combat deployed participants with and without new onset symptoms or diagnosis of PTSD. Multivariable logistic regressions investigated associations between the component summary scores before deployment and new onset symptoms or diagnosis of PTSD using both specific and sensitive criteria.

We performed regression diagnostics, including examining covariates for collinearity and goodness of fit test. All data analyses were performed with SAS statistical software version 9.1 (SAS Institute, Cary, NC).

\section{RESULTS}

There were 55021 participants who completed the baseline (July 2001 to June 2003) and the first followup (June 2004 to February 2006) questionnaires, of whom $22208(40 \%)$ deployed in support of the conflicts in Iraq and Afghanistan. The mean time between baseline and submission of the first follow-up questionnaire was 2.7 years (SD 0.5; median 2.8). To study a more homogenous group of deployers who were exposed to one or more traumatic events during deployment, we removed from the analyses those participants whose first deployment did not occur between baseline and follow-up or who did not report combat exposures $(\mathrm{n}=16$ 172). To examine deployers with no recorded history of symptoms of PTSD, we also removed those who reported a previous physician diagnosis of PTSD $(n=86)$ or who had symptoms of PTSD ( $n=98)$ at baseline. Similarly, we excluded participants who self reported (at follow-up) being diagnosed with PTSD before deployment $(n=11)$ and those with missing baseline or follow-up PTSD, functional health, or covariate data $(n=431)$, leaving 5410 for analysis.

Table 1 shows baseline population characteristics by centile of mental and physical component summary scores. Those whose mental component summary scores were below the 15 th centile were proportionately more likely to be women, younger, less educated, not married, non-officers, to have an occupational position other than combat, health care or functional support (such as technical or electrical repair position), and to report current smoking and have a positive CAGE result. Participants below the 15 th centile for mental component summary score had a mean score of 37.9, compared with 55.4 and 62.4 for the 15 th to 85 th and higher than 85 centile groups, respectively. Those whose physical component summary scores were below the 15 th centile were proportionately more likely to be less educated, black non-Hispanic, non-officers, active duty, serving in the army, and to have an occupational position other than combat, health care or functional support (such as technical or electrical repair position). They were also proportionately more likely to have a positive CAGE result, report current smoking and have three or more combat exposures. The mean physical component summary score was 41.2 for those below the 15 th centile, 55.4 for those in the 15 th to 85 th centile, and 61.3 for those in the highest centile group.

Table 2 shows baseline characteristics by percentage of new onset symptoms or diagnosis of PTSD, using both the specific and sensitive criteria. The table also shows odds ratios and 95\% confidence intervals representing the odds of new onset symptoms or diagnosis of PTSD. With the specific criteria of the DSM-IV, new onset PTSD was identified in 7.3\% (395) of the study group with a sum of 50 points or a physician diagnosis. Using the sensitive criteria of the DSM-IV alone or a physician diagnosis, 8.6\% (457) were identified with new onset PTSD. After adjustment for all other variables in the model, individuals whose baseline mental component summary score was below the 15 th centile were over three times as likely to have new-onset symptoms or diagnosis of PTSD (odds ratio $3.51,95 \%$ confidence interval 2.74 to 4.50 , specific; $3.18,2.50$ to 4.05 , sensitive). Individuals whose baseline physical component summary score was below the 15 th centile were over twice as likely to have new onset symptoms or diagnosis of PTSD (2.22, 1.71 to 2.89 , specific; $2.11,1.64$ to 2.70 , sensitive). Participants who reported three or more combat exposures during their deployment were also more than twice as likely to have new onset symptoms or diagnosis of PTSD by follow-up (2.60, 1.89 to 3.58, specific; $2.32,1.74$ to 3.08 , sensitive). Additionally, women $(2.33,1.80$ to 3.03$)$, current smokers (1.56, 1.21 to 2.01), non-officers (1.77, 1.11 to 2.85$)$, Reserve/National Guard (1.85, 1.47 to 2.33$)$, and army $(2.04,1.39$ to 3.02$)$ members had increased odds for new onset symptoms or diagnosis of PTSD (measures are based on sensitive criteria). Participants of other races or ethnicities (excluding black non-Hispanic) were 1.57 times more likely to have new onset symptoms or diagnosis of PTSD by follow-up compared with white non-Hispanics (1.18 to 2.08, sensitive criteria). 
Table 1|Demographic characteristics of 5410 combat deployed* participants in Millennium Cohort Study by functional status (centile of component score), 2001-6. Figures are numbers (rounded percentage) of participants

Mental component summary score $†$

<15th $(n=811) \quad 15-85$ th $(n=3785) \quad$ 185th $(n=814)$

Physical component summary score $\neq$

<15th $(n=811) \quad 15-85$ th $(n=3787) \quad$ >85th $(n=812)$

41.2

$730(89.7)$

$3200(84.5)$

$585(15.5)$

$197(24.3)$

$585(15.5)$

84 (10.3)

$550(14.5)$

1532 (40.5)

1505 (39.8)

198 (5.2)

101 (12.5)

540 (66.6)

125 (15.4)

110 (13.6)

1859 (49.1)

749 (19.8)

832 (22.0)

36 (4.4)

345 (9.1)

379 (46.7)

432 (53.3)

$1356(35.8)$

2429 (64.2)

$572(70.5)$
$91(11.2)$
$148(18.3)$

2601 (68.7)

342 (9.0)

842 (22.3)

411 (50.7)

171 (21.1)

229 (28.2)

2265 (59.8)

865 (22.9)

655 (17.3)

556 (68.6)

255 (31.4)

3117 (82.4)

668 (17.7)

662 (81.6)

149 (18.4)

2601 (68.7)

1184 (31.3)

275 (33.9)

536 (66.1)

1438 (38.0)

2347 (62.0)

558 (68.8)

129 (15.9)

68 (8.4)

56 (6.9)

$181(22.3)$

86 (10.6)

111 (13.7)

433 (53.4)

$184(22.7)$

$162(20.0)$

465 (57.3)
2449 (64.7)

815 (21.5)

268 (7.1)

253 (6.7)

1135 (30.0)

411 (10.9)

419 (11.1)

1820 (48.1)

1074 (28.4)

744 (19.7)

1967 (52.0)

$187(23.0)$

$187(23.0)$

348 (42.8)

251 (30.8)

28 (3.4)

389 (47.8)

181 (22.2)

165 (20.3)

79 (9.7)

231 (28.4)

583 (71.6)

498 (61.2)

111 (13.6)

205 (25.2)

$545(67.2)$
$117(14.4)$
$149(18.4)$

522 (64.1)

182 (22.4)

110 (13.5)

667 (82.2)

144 (17.8)

55.4

61.3

14

$113(13.9)$

369 (45.5)

293 (36.1)

$36(4.4)$

$536(66.1)$

153 (18.9)

86 (10.6)

36 (4.4)

3209 (84.7)

578 (15.3)

668 (82.3)

144 (17.7)

Combat exposure severity

1 exposure

$\geq 3$ exposures

${ }^{*}$ Combat deployed is defined as at least one deploym

one combat like exposure on follow-up questionnaire.

$\dagger$ All unadjusted associations between scores and individual characteristics significant at $P<0.05$, except association with service component $(P=0.09)$.

$\ddagger$ All unadjusted associations between scores and individual characteristics significant at $\mathrm{P}<0.05$, except association with sex ( $\mathrm{P}=0.07$ ).

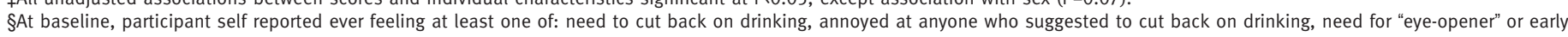

morning drink, and guilty about drinking.

ПCombat exposures included reporting exposure to witnessing death, abuse, maimed soldiers or civilians, prisoners of war, or refugees. 


\section{DISCUSSION}

An identifiable population of combat deployers from a population based military cohort who were below the 15th centile for self reported baseline mental health accounted for $35 \%$ of the incidence of PTSD after combat deployment. Furthermore, $58 \%$ of those with new onset PTSD fell below the 15 th centile for mental or physical health at baseline. There has been much research into comorbidities and decreased mental and physical health associated with symptoms of PTSD. ${ }^{13-101213}$ While we know that combat deployments significantly increase the likelihood of symptoms of PTSD, ${ }^{1819384344}$ little is known about baseline factors, screening factors before deployment, or modifiable factors associated with new onset PTSD.

\section{Limitations and strengths}

The study population consisted of a sample of responders to the Millennium Cohort questionnaire and might not be representative of all combat deployers in the US military population. Investigation of potential biases in the cohort, however, found a well representative military cohort who report reliable data and who are not influenced to participate by poor health before enrolment. ${ }^{22-29}$ Combat exposures were identified with self reported data, which inherently have some recall and reporting biases. Furthermore, the questions used to identify combat exposures were not specific to deployment, so participants might have experienced these exposures at times other than during their deployment. The PTSD checklist-civilian was used to assess symptoms of PTSD, and, while it is a standardised and verified instrument, ${ }^{2841}$ it is a surrogate for a clinician diagnosis and might misclassify PTSD status for some participants.

Despite these limitations, there are many important strengths of this study. To our knowledge, this is the first study to prospectively investigate diminished physical and mental health in relation to new onset symptoms or diagnosis of PTSD. The PTSD checklistcivilian survey data might more accurately capture those with symptoms of PTSD compared with ambulatory or hospital admission data, as many with symptoms might not seek treatment for fear of attached stigma.

\section{Implications}

The US military often operates in a highly dynamic, lethal, and technological environment, making it important for service members to be mentally and physically fit. ${ }^{45}$ In a combat environment, a large volume of visual, auditory, and other information must be interpreted and acted on without hesitation, which requires excellent cognitive abilities, an ability to manage extreme stress, think clearly under pressure, multitask, and remain vigilant for extended times during prolonged periods of high operational tempo. ${ }^{46}{ }^{47} \mathrm{Phy}-$ sical health is equally important because physically fit service members are better prepared to meet the physical rigours associated with military service. Lower physical health status has been associated with some diseases $^{4849}$ and increased injuries. ${ }^{50}$ In addition to the importance for basic health and military readiness, our study provides strong evidence that physical and mental health is essential for prevention of a large portion of PTSD after combat.

To work and function in potentially stressful environments, those seeking to join the US military are screened physically and mentally. Potential candidates are disqualified if they have any of a number of medical conditions or chronic psychological disorders, including PTSD ${ }^{51}$ Therefore, it is not unexpected that service members have better overall physical and mental health than the general US population. ${ }^{52}$ Notwithstanding, there is a broad range in mental and physical health status of service members, as shown in this study.

The normative mean scores for "healthy" US individuals without chronic conditions are 55.8 and 52.5 for mental and physical component summary scores, respectively. ${ }^{35}$ In comparison, mean scores before deployment for those who reported no symptoms or diagnosis of PTSD at baseline or follow-up (54.4. and 54.3 , respectively) are similar to "healthy" individuals, while the mean scores before deployment of those who met the specific criteria for PTSD symptoms or diagnosis at follow-up (51.5 and 48.1, respectively), though still close to the 50 point mean for the US general population, are quite a bit lower and might represent meaningful differences.

While the mean component summary scores of combat deployers below the 15 th centile in this study are low (41.2 for physical, 37.9 for mental), they are much higher than the mean component summary scores of those below the 15 th centile in the general US population (28.4 and 30.9, respectively). ${ }^{35}$ The self reported mental health status of those below the 15 th centile for mental component summary score (37.9) is comparable with that in people who reported ever having depression in the general US population (score 36.8). The self reported physical health status of those scoring below the 15th centile for physical component summary score (41.2) is comparable with those in the general US population who reported ever having cancer or rheumatoid arthritis (mean scores 41.1 and 41.7, respectively). This does not indicate, however, that these service members in these lowest groups have these conditions, it just serves as a comparison to the civilian population. To further investigate the differences of the various component groups, we examined the number of self reported diagnosed conditions on the follow-up survey. Those with physical component summary scores below the 15 th centile had a mean of 1.8 diagnosed conditions compared with 0.9 for those in the 15 th to 85 th centile and 0.6 for those above the 85 th centile. While those below the 15 th centile for the mental component summary score had a mean of 1.5 diagnosed conditions compared with 0.9 for the other two groups. So though these individuals are being deployed, they seem to have diminished health before deployment. This 
Table 2|Percentages and adjusted odds ratios ( $95 \%$ confidence intervals) of new onset PTSD among combat deployed* participants of Millennium Cohort according to specific and sensitive criteria, 2001-6

Specific criteria† $(n=395)$

Baseline characteristics

Centile of mental component summary score (mean score):

«15th («46.2)
$15-85$ th $(46.2-60.4)$
>85th ( $>60.4)$

Centile of physical component summary score (mean score):

\begin{tabular}{lc}
\hline 15 th $(<48.2)$ & 116 \\
\hline $15-85$ th $(48.2-59.7)$ & 221( \\
\hline 85 th $(>59.7)$ & $58(7$
\end{tabular}

Sex:

\begin{tabular}{lr} 
Male & \\
\hline Female & 114 \\
\hline Birth year: &
\end{tabular}

\begin{tabular}{ll}
\hline Pre 1960 & 43 \\
\hline $1960-9$ & 119 \\
\hline $1970-9$ & 184 \\
\hline 1980 forward & 49 \\
\hline
\end{tabular}

Education:

\begin{tabular}{|c|c|c|c|c|}
\hline High school or less & $294(10.6)$ & 1.00 & $334(12.3)$ & 1.00 \\
\hline Some college & $49(4.6)$ & 0.77 (0.53 to 1.12$)$ & $63(6.0)$ & 0.86 (0.61 to 1.21$)$ \\
\hline Bachelor's degree & $34(3.1)$ & 0.60 (0.36 to 1.02$)$ & $40(3.6)$ & 0.60 (0.37 to 0.98$)$ \\
\hline Advanced degree & $18(3.9)$ & 1.10 (0.54 to 2.22$)$ & $20(4.4)$ & 1.07 (0.56 to 2.06$)$ \\
\hline \multicolumn{5}{|l|}{ Marital status: } \\
\hline Not married & $179(9.1)$ & 1.00 & $208(10.8)$ & 1.00 \\
\hline Married & $216(6.3)$ & 1.13 (0.87 to 1.46$)$ & $249(7.3)$ & 1.12 (0.88 to 1.43$)$ \\
\hline \multicolumn{5}{|l|}{ Race/ethnicity: } \\
\hline White non-Hispanic & $263(7.2)$ & 1.00 & $306(8.5)$ & 1.00 \\
\hline Black non-Hispanic & $50(9.2)$ & $1.22(0.85$ to 1.75$)$ & $55(10.3)$ & 1.19 (0.84 to 1.68$)$ \\
\hline Other & $82(6.9)$ & 1.55 (1.15 to 2.09$)$ & $96(8.1)$ & 1.57 (1.18 to 2.08 ) \\
\hline \multicolumn{5}{|l|}{ Smoking status } \\
\hline Never smoker & $190(5.9)$ & 1.00 & $217(6.9)$ & 1.00 \\
\hline Past smoker & $90(7.4)$ & 1.16 (0.88 to 1.54$)$ & $104(8.7)$ & 1.21 (0.93 to 1.57$)$ \\
\hline Current smoker & $115(11.6)$ & 1.38 (1.05 to 1.81$)$ & $136(14.1)$ & 1.56 (1.21 to 2.01$)$ \\
\hline \multicolumn{5}{|l|}{ Alcohol/CAGE**: } \\
\hline No & $297(6.8)$ & 1.00 & $348(8.1)$ & 1.00 \\
\hline Yes & $98(9.5)$ & 1.13 (0.87 to 1.47$)$ & $109(11.0)$ & 1.14 (0.89 to 1.46$)$ \\
\hline \multicolumn{5}{|l|}{ Military rank: } \\
\hline Non-officer & $344(9.0)$ & $1.80(1.07$ to 3.01$)$ & $397(10.6)$ & 1.77 (1.11 to 2.85$)$ \\
\hline Officer & $51(3.2)$ & 1.00 & $60(3.8)$ & 1.00 \\
\hline \multicolumn{5}{|l|}{ Service component: } \\
\hline Reserve/National Guard & $172(8.5)$ & 1.78 (1.39 to 2.28$)$ & $205(10.3)$ & 1.85 (1.47 to 2.33 ) \\
\hline Active duty & $223(6.6)$ & 1.00 & $252(7.6)$ & 1.00 \\
\hline \multicolumn{5}{|l|}{ Branch of service: } \\
\hline Army & $323(9.1)$ & $1.87(1.23$ to 2.85$)$ & $373(10.7)$ & 2.04 (1.39 to 3.02$)$ \\
\hline Air force & $35(3.1)$ & 1.00 & $41(3.7)$ & 1.00 \\
\hline Navy/coast guard & $17(4.4)$ & 1.14 (0.60 to 2.17$)$ & $21(5.5)$ & 1.39 (0.77 to 2.51$)$ \\
\hline Marine corps & $20(5.6)$ & 1.22 (0.64 to 2.31$)$ & $22(6.3)$ & 1.25 (0.68 to 2.29$)$ \\
\hline \multicolumn{5}{|l|}{ Occupational category: } \\
\hline Combat specialists & $87(5.6)$ & 1.00 & $101(6.6)$ & 1.00 \\
\hline Healthcare specialists & $37(6.5)$ & 0.84 (0.54 to 1.30 ) & $36(6.4)$ & 0.67 (0.44 to 1.04$)$ \\
\hline Functional support & $51(8.0)$ & 1.01 (0.68 to 1.51$)$ & $59(9.5)$ & 1.01 (0.70 to 1.47$)$ \\
\hline Other occupations & $220(8.3)$ & 1.08 (0.81 to 1.43$)$ & $261(10.1)$ & 1.10 (0.84 to 1.43$)$ \\
\hline
\end{tabular}

\begin{tabular}{cccc}
$156(19.2)$ & $3.51(2.74$ to 4.50$)$ & $158(21.5)$ & $3.18(2.50$ to 4.05$)$ \\
$199(5.3)$ & 1.00 & $252(6.7)$ & 1.00 \\
\hline $40(4.9)$ & $0.87(0.60$ to 1.24$)$ & $47(5.8)$ & $0.80(0.57$ to 1.12$)$
\end{tabular}

$16(14.3) \quad 2.22(1.71$ to 2.89$)$

0.87 (0.63 to 1.21$)$

2.11 (1.64 to 2.70$)$

1.00

0.89 (0.65 to 1.21$)$

$281(6.2)$

$114(13.2)$

2.26 (1.72 to 2.98$)$

$131(15.4)$

1.00

2.33 (1.80 to 3.03$)$

$43(5.3)$

1.00

$119(5.5)$

0.84 (0.57 to 1.24$)$

$49(6.1)$

1.00

$144(6.7)$

0.95 (0.66 to 1.36$)$

$184(8.7)$

1.20 (0.80 to 1.81$)$

$206(10.0)$

58 (18.5)

1.26 (0.86 to 1.85 )

1.59 (0.96 to 2.62 )

9 (15.0)

1.38 (0.81 to 2.35 )

(3)

$63(6.0)$

$40(3.6)$

1.10 (0.54 to 2.22$)$

Advanced degre

$179(9.1)$

$263(7.2)$

$50(9.2)$

$55(10.3)$

19 (0.84 to 1.68$)$

Othe

$190(5.9)$

1.00

$217(6.9)$

$104(8.7)$

1.21 (0.93 to 1.57 )

1.16 (0.88 to 1.54$)$

(1)

$348(8.1)$

$60(3.8)$

205 (10.3)

$373(10.7)$

$41(3.7)$

$1.39(0.77$ to 2.51$)$

1.14 (0.60 to 2.17)

$21(5.5)$

$101(6.6)$

$59(9.5)$

1.01 (0.70 to 1.47$)$

1.08 (0.81 to 1.43$)$ 


\begin{tabular}{|c|c|c|c|c|}
\hline \multirow[b]{2}{*}{ Baseline characteristics } & \multicolumn{2}{|c|}{ Specific criteria† $(n=395)$} & \multicolumn{2}{|c|}{ Sensitive criteriał $(n=457)$} \\
\hline & No $(\% \S)$ & ORT $(95 \% \mathrm{Cl})$ & No $(\% \S)$ & ORT $(95 \% \mathrm{Cl})$ \\
\hline \multicolumn{5}{|c|}{ Combat exposure severityłt: } \\
\hline 1 exposure & $55(3.7)$ & 1.00 & $74(5.1)$ & 1.00 \\
\hline 2 exposures & $58(5.6)$ & $1.43(0.96$ to 2.11$)$ & $60(5.9)$ & 1.09 (0.76 to 1.57$)$ \\
\hline$\geq 3$ exposures & $282(9.8)$ & 2.60 (1.89 to 3.58$)$ & $323(11.4)$ & 2.32 (1.74 to 3.08$)$ \\
\hline
\end{tabular}

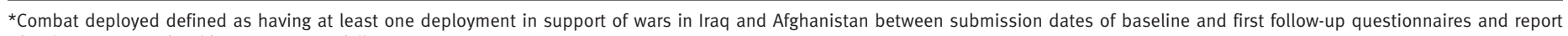
of at least one combat-like exposure on follow-up questionnaire.

TPTSD symptoms based on PCL-C with DSM-IV criteria and 50/85 points possible or diagnosis of PTSD within three years before completion of follow-up questionnaire.

†PTSD symptoms based on PCL-C and DSM-IV criteria or diagnosis of PTSD within three years before completion of follow-up questionnaire.

§Percentage of participants with PTSD within baseline category.

TAdjusted for all variables listed.

presents an easily identifiable subpopulation for screening before deployment.

Consistent with trends reported in previous research, those with mental component summary scores below the 15th centile were proportionately more likely to be women, younger, less educated, not married, current smokers, problem drinkers, and nonofficers. $^{3553-55}$ Of these 811 participants, 19\% were assessed as having symptoms or diagnosis of PTSD after deployment, more than double the rate of PTSD among the study population. Similar to previous research, those who self reported physical component summary scores below the 15th centile in this study were proportionately more likely be less educated, current smokers, non-officers, and active duty service members. ${ }^{53546}$ Of these participants with the lowest physical component summary scores, 14\% were assessed with symptoms or diagnosis of PTSD after deployment at follow-up. There were 157 who fell below the lowest 15 th centile category for both summary scores. Of these, 41 (26\%) self reported symptoms or diagnosis of PTSD after deployment at follow-up - a rate more than three times that of other combat deployers.

\section{Summary \\ After adjustment for baseline behavioural characteris- tics, such as smoking and screening positive for CAGE, as well as other demographic and occupational charac- teristics, we found a threefold increase in new onset symptoms or diagnosis of PTSD among those below the 15 th centile of mental health. Nearly as surprising, after adjustment we found a twofold increase of new onset symptoms or diagnosis of PTSD among those below the 15 th centile of physical health.}

\section{WHAT IS ALREADY KNOWN ON THIS TOPIC}

Post-traumatic stress disorder (PTSD) is associated with reduced mental and physical health status as well as many comorbidities

As previous studies have mostly used retrospective or cross sectional data it is unclear if those with decreased mental or physical health are more vulnerable to developing PTSD

\section{WHAT THIS STUDY ADDS}

Diminished mental or physical health status before combat deployment is strongly associated with an increased risk of PTSD after deployment
While sex, race/ethnicity, smoking status, military rank, service component, branch of service, combat exposures, and low physical component summary score were significantly associated with PTSD after deployment (based on the sensitive and specific criteria), the largest risk factor for developing new onset PTSD in this study was low mental health scores at baseline before deployment. Among previous studies of deployed military members, severity of combat has been found to be one of the strongest predictors of PTSD. ${ }^{113857}$ Most of these studies, however, used retrospective or cross sectional designs, making it difficult to examine the relation between characteristics before deployment and PTSD after deployment. Previous studies have also consistently identified female sex, adverse childhood experiences, lack of social support, and younger age as risk factors for developing PTSD. ${ }^{215}{ }^{1858-64}$ In a meta-analysis, however, psychological processes during the trauma, such as dissociation and negative emotional response, were reported to be most strongly associated with PTSD. ${ }^{16}$ Mental health status after a traumatic or stressful experience might be shaped by a multitude of integrated factors, including perception, interpretation, and evaluation of the traumatic event, coping strategies used, and other personal, social, and cultural factors. ${ }^{65}$ Some of these factors are associated with lower mental health status, including female sex, adverse childhood experiences, and younger age. ${ }^{356667}$ In addition, individuals with diminished mental health before a traumatic experience might be more likely to react poorly to the event, including having a negative response and dissociative experience. Diminished mental health status before a stressful experience might therefore be an underlining factor that not only affects the reaction during the traumatic event but possibly also the coping strategies after the event. Decreased mental health status before a traumatic experience might result in a synergistic effect that leads to the development of PTSD.

Post-traumatic stress disorder is a debilitating disorder that is associated with considerable morbidity. It is essential to determine risk factors for PTSD to provide intervention services before, during, and after military deployment. We have identified an at risk population whose functional health seems to predict vulnerability to PTSD after combat deployment. In theory, such a 
population could be targeted for PTSD prevention programmes, early intervention after exposure to stress, or even protection from stressful exposures, when possible.

In addition to the authors, the Millennium Cohort Study Team includes Lacy Farnell, Gia Gumbs, Isabel Jacobson, Molly Kelton, Travis Leleu, Jamie McGrew, Katherine Snell, Beverly Sheppard, Steven Spiegel, Kari Welch, Martin White, James Whitmer, and Charlene Wong, from the Department of Defense Center for Deployment Health Research, Naval Health Research Center, San Diego, CA; Paul J Amoroso, from the Madigan Army Medical Center, Tacoma, WA; Edward I Boyko, from the Seattle Epidemiologic Research and Information Center, Veterans Affairs Puget Sound Health Care System, Seattle, WA; Gary D Gackstetter, from the Department of Preventive Medicine and Biometrics, Uniformed Services University of the Health Sciences, Bethesda, and the Analytic Services (ANSER), Arlington, VA; Gregory C Gray, from the College of Public Health, University of lowa, Iowa City, IA; Tomoko I Hooper, from the Department of Preventive Medicine and Biometrics, Uniformed Services University of the Health Sciences, Bethesda; and James R Riddle, from the US Air Force Research Laboratory, Wright-Patterson Air Force Base, $\mathrm{OH}$. We are indebted to the Millennium Cohort Study participants, without whom these analyses would not be possible. We thank Scott L Seggerman and Greg D Boyd from the Management Information Division, US Defense Manpower Data Center, Seaside, CA; Michelle Stoia from the Naval Health Research Center; and all the professionals from the US Army Medical Research and Materiel Command, especially those from the Military Operational Medicine Research Program, Fort Detrick, MD. We appreciate the support of the Henry M Jackson Foundation for the Advancement of Military Medicine, Rockville, MD.

Contributors: All authors designed the study, analysed and interpreted the data, drafted and critically revised the manuscript, and approved the final version. CAL, TCS, and MAKR acquired the data. CAL, TCS, and BS carried out the statistical analysis. CAL is guarantor.

Funding: This represents Naval Health Research Center report 08-07, supported by the US Department of Defense, under work unit No 60002 Funding sources did not play any other role. The views expressed in this article are those of the authors and do not reflect the official policy or position of the US Department of the Navy, US Department of the Army, US Department of the Air Force, US Department of Defense, US Department of Veterans Affairs, or the US Government.

Competing interests: None declared.

Ethical approval: The Millennium Cohort Study was approved by the Institutional Review Board of the Naval Health Research Center (Protocol NHRC.2000.0007). All participants gave informed consent.

1 Holbrook TL, Hoyt DB, Stein MB, Sieber WJ. Perceived threat to life predicts posttraumatic stress disorder after major trauma: risk factors and functional outcome. / Trauma 2001;51:287-93.

2 Iversen AC, Fear NT, Ehlers A, Hacker Hughes J, Hull L, Earnshaw M, et al. Risk factors for post-traumatic stress disorder among UK Armed Forces personnel. Psychol Med 2008;38:511-22.

3 Erbes C, Westermeyer J, Engdahl B, Johnsen E. Post-traumatic stress disorder and service utilization in a sample of service members from Iraq and Afghanistan. Mil Med 2007;172:359-63.

4 Rapaport MH, Clary C, Fayyad R, Endicott J. Quality-of-life impairment in depressive and anxiety disorders. Am J Psychiatry 2005;162:1171-8

5 Butterfield MI, Forneris CA, Feldman ME, Beckham JC. Hostility and functional health status in women veterans with and without posttraumatic stress disorder: a preliminary study. J Trauma Stress 2000;13:735-41.

6 Jamil H, Nassar-McMillan SC, Salman WA, Tahar M, Jamil LH. Iraqi Gulf War veteran refugees in the US: PTSD and physical symptoms. Soc Work Health Care 2006;43:85-98.

7 Mancino MJ, Pyne JM, Tripathi S, Constans J, Roca V, Freeman T. Quality-adjusted health status in veterans with posttraumatic stress disorder. J Nerv Ment Dis 2006;194:877-9.

8 Barrett DH, Doebbeling CC, Schwartz DA, Voelker MD, Falter KH, Woolson RF, et al. Posttraumatic stress disorder and self-reported physical health status among U.S. Military personnel serving during the Gulf War period: a population-based study. Psychosomatics 2002;43:195-205.

9 Dobie DJ, Kivlahan DR, Maynard C, Bush KR, Davis TM, Bradley KA Posttraumatic stress disorder in female veterans: association with self-reported health problems and functional impairment. Arch Intern Med 2004;164:394-400.
10 Zatzick DF, Marmar CR, Weiss DS, Browner WS, Metzler TJ, Golding JM, et al. Posttraumatic stress disorder and functioning and quality of life outcomes in a nationally representative sample of male Vietnam veterans. Am J Psychiatry 1997;154:1690-5.

11 Hoge CW, Terhakopian A, Castro CA, Messer SC, Engel CC. Association of posttraumatic stress disorder with somatic symptoms, health care visits, and absenteeism among Iraq war veterans. Am J Psychiatry 2007;164:150-3.

12 Zatzick DF, Weiss DS, Marmar CR, Metzler TJ, Wells K, Golding JM, et al. Post-traumatic stress disorder and functioning and quality of life outcomes in female Vietnam veterans. Mil Med 1997:162:661-5.

13 Baker DG, Mendenhall CL, Simbartl LA, Magan LK, Steinberg JL. Relationship between posttraumatic stress disorder and selfreported physical symptoms in Persian GulfWar veterans. Arch Intern Med 1997;157:2076-8.

14 Wagner AW, Wolfe J, Rotnitsky A, Proctor SP, Erickson DJ. An investigation of the impact of posttraumatic stress disorder on physical health. I Trauma Stress 2000;13:41-55.

15 Brewin CR, Andrews B, Valentine JD. Meta-analysis of risk factors for posttraumatic stress disorder in trauma-exposed adults. J Consult Clin Psychol 2000;68:748-66.

16 Ozer EJ, Best SR, Lipsey TL, Weiss DS. Predictors of posttraumatic stress disorder and symptoms in adults: a meta-analysis. Psycho Bull 2003:129:52-73.

17 Storr CL, lalongo NS, Anthony JC, Breslau N. Childhood antecedents of exposure to traumatic events and posttraumatic stress disorder. Am J Psychiatry 2007;164:119-25.

18 Smith TC, Wingard DL, Ryan MA, Kritz-Silverstein D, Slymen DJ, Sallis JF. Prior assault and posttraumatic stress disorder after combat deployment. Epidemiology 2008;19:505-12.

19 Smith TC, Ryan MAK, Wingard DL, Slymen DJ, Sallis JF, Kritz-Silverstein D. New onset and persistent symptoms of posttraumatic stress disorder self-reported after deployment and combat exposures: prospective population-based US military cohort study. BMJ 2008;336:366-71.

20 Gray GC, Chesbrough KB, Ryan MA, Amoroso P, Boyko EJ, Gackstetter GD, et al. The Millennium Cohort Study: a 21-yea prospective cohort study of 140,000 military personnel. Mil Med 2002;167:483-8.

21 Ryan MA, Smith TC, Smith B, Amoroso P, Boyko EJ, Gray GC, et al. Millennium Cohort: enrollment begins a 21-year contribution to understanding the impact of military service. J Clin Epidemio 2007;60:181-91.

22 LeardMann CA, Smith B, Smith TC, Wells TS, Ryan MA. Smallpox vaccination: comparison of self-reported and electronic vaccine records in the Millennium Cohort Study. Hum Vaccin 2007;3:245-51.

23 Riddle JR, Smith TC, Smith B, Corbeil TE, Engel CC, Wells TS, et al. Millennium Cohort: the 2001-2003 baseline prevalence of mental disorders in the U.S. military. J Clin Epidemiol 2007;60:192-201.

24 Smith B, Leard CA, Smith TC, Reed RJ, Ryan MA. Anthrax vaccination in the Millennium Cohort: validation and measures of health. Am J Prev Med 2007;32:347-53.

25 Smith B, Smith TC, Gray GC, Ryan MA. When epidemiology meets the internet: web-based surveys in the Millennium Cohort Study. Am Epidemiol 2007;166:1345-54.

26 Smith B, Wingard DL, Ryan MAK, Macera CA, Patterson TL, Slymen D]. US military deployment during 2001-2006: comparison of subjective and objective data sources in a large prospective health study. Ann Epidemiol 2007;17:976-82.

27 Smith TC, Jacobson IG, Smith B, Hooper TI, Ryan MA, Team FI. The occupational role of women in military service: validation of occupation and prevalence of exposures in the Millennium Cohort Study. Int J Environ Health Res 2007;17:271-84

28 Smith TC, Smith B, Jacobson IG, Corbeil TE, Ryan MA. Reliability of standard health assessment instruments in a large, populationbased cohort study. Ann Epidemiol 2007;17:525-32.

29 Wells T, Smith TC, Reed RJ, Spooner C, Smith B, Jacobson I, et al. Prio health care utilization as a determinant to enrollment in a twentyyear prospective study, the Millennium Cohort Study. Eur J Epidemio 2008;23:79-87.

30 Kazis LE, Lee A, Spiro A, III, Rogers W, Ren XS, Miller DR, et al. Measurement comparisons of the medical outcomes study and veterans SF-36 health survey. Health Care Financ Rev 2004;25:43-58

31 Ware JE, Kosinski M, Gandek B. SF-36 health survey: manual and interpretation guide Lincoln, RI: QualityMetric, 2000.

32 Kazis LE, Miller DR, Clark JA, Skinner KM, Lee A, Ren XS, et al. Improving the response choices on the veterans SF-36 health survey role functioning scales: results from the Veterans Health Study. J Ambul Care Manage 2004;27:263-80.

33 Kazis LE, Miller DR, Skinner KM, Lee A, Ren XS, Clark JA, et al. Patientreported measures of health: the Veterans Health Study. J Ambul Care Manage 2004;27:70-83 
34 Ware JE Jr, Sherbourne CD. The MOS 36-item short-form health survey (SF-36). I. Conceptual framework and item selection. Med Care 1992;30:473-83.

35 Ware JE, Kosinski M. SF-36 physical and mental health summary scales: a manual for users of version 1. 2nd ed. Lincoln, Rl: QualityMetric, 2001.

36 Weather FW, Litz BJ, Herman DS, Huska JA, Keane TM. PTSD checklist (PCL): reliability, validity, and diagnostic utility. Paper presented at the Annual Meeting of International Society for Traumatic Stress Studies, 1993. www.pdhealth.mil/library/downloads/ PCL_sychometrics.doc.

37 Blanchard EB, Jones-Alexander J, Buckley TC, Forneris CA. Psychometric properties of the PTSD checklist (PCL). Behav Res Ther 1996;34:669-73.

38 Hoge CW, Castro CA, Messer SC, McGurk D, Cotting DI, Koffman RL. Combat duty in Iraq and Afghanistan, mental health problems, and barriers to care. N Engl J Med 2004;351:13-22.

39 Wright KM, Huffman AH, Adler AB, Castro CA. Psychological screening program overview. Mil Med 2002;167:853-61

40 American Psychiatric Association. Diagnostic and statistical manual of mental disorders. 4th ed. Washington, DC: American Psychiatric Association, 1994.

41 Brewin CR. Systematic review of screening instruments for adults at risk of PTSD. / Trauma Stress 2005;18:53-62.

42 Bush B, Shaw S, Cleary P, Delbanco TL, Aronson MD. Screening for alcohol abuse using the CAGE questionnaire. Am J Med 1987;82:231-5.

43 Milliken CS, Auchterlonie JL, Hoge CW. Longitudinal assessment of mental health problems among active and reserve component soldiers returning from the Iraq war. JAMA 2007;298:2141-8.

44 Hoge CW, Auchterlonie JL, Milliken CS. Mental health problems, use of mental health services, and attrition from military service after returning from deployment to Iraq or Afghanistan. JAMA 2006;295:1023-32.

45 Krueger GP, Banderet LE. Implications for studying team cognition and team performance in network-centric warfare paradigms. Aviat Space Environ Med 2007;78(suppl 5):B58-62.

46 Albery WB. Multisensory cueing for enhancing orientation information during flight. Aviat Space Environ Med 2007;78(suppl 5):B186-90.

47 Fiedler ER. Operational processes and cognitive mapping. Aviat Space Environ Med 2005;76(suppl 7):C4-6.

48 Edwards KM, Ziegler MG, Mills PJ. The potential anti-inflammatory benefits of improving physical fitness in hypertension. J Hyperten 2007; 25:1533-42.

49 Katzmarzyk PT, Craig CL, Gauvin L. Adiposity, physical fitness and incident diabetes: the physical activity longitudinal study. Diabetologia 2007;50:538-44.

50 Harwood GE, Rayson MP, Nevill AM. Fitness, performance, and risk of injury in British Army officer cadets. Mil Med 1999;164:428-34.

51 Department of Defense. Department of Defense instruction: medical standards for appointment, enlistment, or induction into the armed forces.

2005. www.dtic.mil/whs/directives/corres/pdf/613004p.pdf/.

52 Smith TC, Zamorski M, Smith B, Riddle JR, LeardMann CA, Wells TS, et al. The physical and mental health of a large military cohort: baseline functional health status of the Millennium Cohort. BMC Public Health 2007;7:340.
53 Borzecki AM, Lee A, Kalman D, Kazis LE. Do poor health behaviors affect health-related quality of life and healthcare utilization among veterans? The Veterans Health Study. J Ambul Care Manage 2005;28:141-56.

54 Ismail K, Blatchley N, Hotopf M, Hull L, Palmer I, Unwin C, et al. Occupational risk factors for ill health in Gulf veterans of the United Kingdom. J Epidemiol Community Health 2000;54:834-8.

55 Voelker MD, Saag KG, Schwartz DA, Chrischilles E, Clarke WR, Woolson RF, et al. Health-related quality of life in Gulf War era military personnel. Am J Epidemiol 2002;155:899-907.

56 Barrett DH, Boehmer TK, Boothe VL, Flanders WD, Barrett DH. Health related quality of life of U.S. military personnel: a population-based study. Mil Med 2003;168:941-7.

57 Kang HK, Natelson BH, Mahan CM, Lee KY, Murphy FM. Posttraumatic stress disorder and chronic fatigue syndrome-like illness among Gulf War veterans: a population-based survey of 30,000 veterans. Am J Epidemiol 2003;157:141-8.

58 Breslau N, Davis GC, Andreski P, Peterson E. Traumatic events and posttraumatic stress disorder in an urban population of young adults. Arch Gen Psychiatry 1991;48:216-22.

59 Gahm GA, Lucenko BA, Retzlaff P, Fukuda S. Relative impact of adverse events and screened symptoms of posttraumatic stress disorder and depression among active duty soldiers seeking mental health care. / Clin Psychol 2007;63:199-211.

60 Koenen KC, Lyons MJ, Goldberg J, Simpson J, Williams WM, Toomey R, et al. Co-twin control study of relationships among combat exposure, combat-related PTSD, and other mental disorders. J Trauma Stress 2003;16:433-8

61 Richardson JD, Naifeh JA, Elhai JD. Posttraumatic stress disorder and associated risk factors in Canadian peacekeeping veterans with health-related disabilities. Can J Psychiatry 2007;52:510-8.

62 Cabrera OA, Hoge CW, Bliese PD, Castro CA, Messer SC. Childhood adversity and combat as predictors of depression and posttraumatic stress in deployed troops. Am J Prev Med 2007;33:77-82.

63 Clancy CP, Graybeal A, Tompson WP, Badgett KS, Feldman ME, Calhoun PS, et al. Lifetime trauma exposure in veterans with militaryrelated posttraumatic stress disorder: association with current symptomatology. J Clin Psychiatry 2006;67:1346-53.

64 King DW, King LA, Foy DW, Gudanowski DM. Prewar factors in combat-related posttraumatic stress disorder: structural equation modeling with a national sample of female and male Vietnam veterans. J Consult Clin Psychol 1996;64:520-31.

65 Olff M, Langeland W, Gersons BP. Effects of appraisal and coping on the neuroendocrine response to extreme stress. Neurosci Biobehav Rev 2005;29:457-67.

66 Edwards VJ, Holden GW, Felitti VJ, Anda RF. Relationship between multiple forms of childhood maltreatment and adult mental health in community respondents: results from the Adverse Childhood Experiences Study. Am J Psychiatry 2003;160:1453-60.

67 Felitti VJ, Anda RF, Nordenberg D, Williamson DF, Spitz AM, Edwards V, et al. Relationship of childhood abuse and household dysfunction to many of the leading causes of death in adults. The Adverse Childhood Experiences (ACE) Study. Am J Prev Med 1998;14:245-58.

Accepted: 19 December 2008 